\title{
As noções de Polidoxia e de diferenciais de poder no contexto da relação entre imaginários e diálogos inter- religiosos.
}

\author{
The notions of polidoxy and of power differentials in the context of the \\ relationship between imaginaries and interreligious dialogues.
}

\section{Cláudio de Oliveira Ribeiro*}

\section{Resumo}

A pesquisa procurou sistematizar duas noções em torno das relações inter-religiosas que visam desconstruir imaginários de corte idealista que muitas vezes emergem de práticas e de formas de ecumenismo inter-religioso: os diferenciais de poder presentes na sociedade e nas relações inter-religiosas e a concepção de polidoxia que evitaria interpretações e ações dicotômicas e bipolares. Metodologicamente, recorremos ao processo de sínteses de perspectivas oriundas dos estudos culturais pós-coloniais realizados por diferentes autores e à crítica teológica feminista de Kwok Pui-Lan. Entre os resultados da pesquisa estão as bases teóricas para as análises que dão destaque aos diferenciais de poder presentes também nas relações inter-religiosas que uma vez identificados, assumidos e equacionados criticamente poderiam atenuar a reprodução de formas veladas de dominação, na medida em que tais formas, contraditoriamente, também estão presentes no espectro do diálogo inter-religioso. Outro é uma elucidação da concepção de polidoxia, que, por intermédio da crítica e do desmascaramento do pensamento único, visa a ultrapassar o binômio ortodoxia/heresia, que em geral inibe a efetivação de um diálogo inter-religioso e cultural autêntico. A divindade, nesta perspectiva, é compreendida em termos de multiplicidade, irrestringibilidade e relacionalidade.

Palavras-chave: Polidoxia; diferenciais de poder; Kwok Pui-Lan; estudos culturais pós-coloniais.

\begin{abstract}
The research sought to systematize two notions around interreligious relations which aim to deconstruct imaginaries of an idealist tendency that often emerge from practices and forms of inter-religious ecumenism: (1) that of power differentials present in society and in interreligious relations and (2) the concept of polidoxy, which would avoid dichotomous and bipolar interpretations and actions. Methodologically, we adopted the process of synthesis of perspectives derived from postcolonial cultural studies - by different authors - and from the feminist theological critique of Kwok Pui-Lan. Among the results of the research are the theoretical bases for the analysis that highlight the power differentials also present in inter-religious relationships. These, as they are critically identified, admitted and evaluated, could attenuate the reproduction of veiled forms of domination, since such forms, contradictorily, are also present in the inter-religious dialogue spectrum. Another result is the clarification of the polidoxy concept, which, through the criticism of the single thought and its unmasking aims to overcome the binomial orthodoxy / heresy. This usually inhibits the realization of an authentic inter-religious and cultural dialogue. The deity, in this approach, is understood in terms of multiplicity, unrestrainability and relationality.
\end{abstract}

Keywords: Polidoxy; power differentials; Kwok Pui-Lan; postcolonial cultural studies.

Artigo recebido em 10 de novembro de 2016 e aprovado em 13 de março de 2017.

* Doutor (2000) e mestre (1994) em Teologia (PUC Rio) e bacharelado em Teologia (1985) no Seminário Metodista Cesar Dacorso Filho, RJ. Tem experiência docente e de pesquisa e é professor titular de Teologia e Ciências da Religião da Universidade Metodista de São Paulo. País de Origem: Brasil. E-mail: claudio.ribeiro@metodista.br. 


\section{Introdução}

As reflexões a seguir procuram sistematizar algumas noções em torno das relações inter-religiosas que visam contribuir para a desconstrução de imaginários de corte idealista que, muitas vezes, emergem de práticas e de formas de ecumenismo inter-religioso e geram formas veladas de dominação, ainda que sejam, contraditoriamente, gestadas em perspectiva inter-religiosa.

Consideramos que, para este debate, um dos elementos que se revela crucial é o foco nos diferenciais de poder presentes na sociedade em geral e também nas relações inter-religiosas. Tentaremos mostrar que tais diferenciais de poder, uma vez identificados, assumidos e equacionados criticamente, poderiam compor um quadro analítico que cooperaria para se atenuar as referidas formas veladas de dominação e contribuir com a recriação de imaginários.

Outro elemento de destaque em nossas análises é a concepção de polidoxia. Ela evitaria interpretações e ações dicotômicas e bipolares no tocante às aproximações inter-religiosas. Constituída por intermédio da crítica e do desmascaramento do pensamento único, a polidoxia visa a ultrapassar o binômio ortodoxia/heresia, que em geral inibe a efetivação de um diálogo inter-religioso e cultural autêntico. Ela realça as compreensões de fé e as práticas religiosas em termos de multiplicidade, irrestringibilidade e relacionalidade.

Os passos que demos na pesquisa fundamentam-se em um processo de sínteses de perspectivas teóricas oriundas dos estudos culturais pós-coloniais, realizados por variados autores provenientes de diferentes continentes e contextos, inclusive o latino-americano, com destaque para a crítica teológica feminista de Kwok Pui-Lan. A referência prática das reflexões está firmada na observação e no acompanhamento de diversas experiências inter-religiosas no Brasil. 


\section{A objetivização dos diferencias de poder nas análises das experiências inter- religiosas}

Levando em conta a realidade dos movimentos inter-religiosos no Brasil, em especial as suas interfaces com as demandas sociais (RIBEIRO, 2016), defenderemos a importância da identificação dos diferencias de poder nestas análises considerando quatro aspectos: (i) a crítica à noção de Ocidente e ao conceito moderno de religião, (ii) a força religiosa do capitalismo, (iii) o pluralismo religioso no contexto da globalização, e (iv) como as experiências inter-religiosas podem gerar imaginários críticos em relação ao poder imperial exercido na sociedade e reforçar os processos de globalização contra-hegemônica.

\subsection{Crítica à noção de Ocidente e ao conceito moderno de religião}

Stuart Hall, figura de destaque dos estudos culturais, em seu livro Formations of Modernity (1992), articula a construção do "Ocidente", usando a criativa expressão "O Ocidente e o Resto" (West and Rest"). Tal concepção é formada por um padrão de pensamento e de linguagem que, desde a sua gênese, é marcada por relações econômicas de dominação. As análises científicas sobre o pluralismo religioso e sobre os decorrentes diálogos ou conflitos que emergem deste quadro não podem, a nosso ver, prescindir desta perspectiva. Mesmo porque, para se usar uma expressão popular: ninguém entende mais do "resto" do que os grupos que cultivam formas excludentes e sectárias que marcam as identidades rígidas, ideológicas e conflitivas presentes no cenário de pluralismo religioso. No entanto, mesmo as experiências de diálogo inter-religioso, ainda que abertas e marcadas por lógicas de alteridade, também estão sujeitas à reprodução dos imaginários que surgiram com a formação do Ocidente.

Neste contexto de configuração de culturas ocorre um duplo processo. O Ocidente é ao mesmo tempo um produto dos meios históricos de domínio, bem como uma ferramenta/paradigma para exercer este mesmo domínio. Nas palavras 
do autor: "A ideia de 'o Ocidente' tornou-se tanto o fator de organização em um sistema de relações globais de poder quanto o conceito de organização de uma forma total de se pensar e de se falar" (HALL, 1992, p. 187). Estamos diante de um sistema de representação e de um conceito cujo núcleo central está muito perto de uma ideologia. Esta construção ocorreu ao longo do processo de constituição e de desenvolvimento do sistema econômico capitalista. A crescente coesão interna que resultou de conflitos com outros povos e de contraste com o mundo externo contribuiu para se forjar um novo senso de identidade. A concepção religiosa europeia cristã é um dos elementos cruciais desta coesão. Tal concepção marca nos dias de hoje diferenciais de poder que interagem diretamente nos imaginários e nas práticas decorrentes dos diálogos inter-religiosos, especialmente em função da participação de grupos religiosos constituídos por grupos subalternos, sobretudo os de matrizes afro-brasileiras.

Esse processo atravessou os continentes, sobretudo pelos empreendimentos coloniais e imperiais e selou o cristianismo ocidental com as marcas de domínio e de hegemonia, por vezes violenta, por vezes dissimulada. Na medida em que se fortalecem, nos diferentes continentes, formas de aproximação inter-religiosa entre grupos cristãos e de outras religiões, em geral, como já mencionado, mergulhadas em culturas subalternas, os elementos que marcam os diferenciais de poder entre elas precisam ser identificados, assumidos nos processos dialogais e equacionados de forma pertinente. Caso tal processo de identificação e equacionamento não seja feito, podem-se gerar formas artificiais de relacionamento entre os grupos, podendo inclusive ocultar novas formas de domínio.

Outro aspecto de destaque dentro deste contexto de ressignificações é o fato do conceito moderno de religião, articulado com a noção ideológica do Ocidente, e em geral adaptado aos cristianismos tradicionais, não corresponder às necessidades de avaliações mais apuradas das religiões tradicionais e populares. Nesse sentido, consideramos urgente uma crítica ao conceito moderno de religião que, por ser compartimentalizado e não valorizar a complexidade e integralidade 
da vida, não favorece as compreensões mais orgânicas e integradoras dos espaços cotidianos, como é o caso de expressões religiosas afro-brasileiras e orientais, entre outras. Embora a cultura moderna tenha se autoafirmado a partir de um discurso pretensamente secular e secularizante - ao buscar uma delimitação do espaço específico da religião - o que as análises têm mostrado é um deslocamento do religioso para fora de suas esferas tradicionais, podendo ser identificado nas práticas econômicas, nas formas de entretenimento e outras dimensões da vida secular. O concretamente experimentado acontece nos entre-lugares das culturas, o que abarca o cotidiano e as fronteiras das diferentes dimensões da vida.

Com esta visão, entendemos ser possível interpretar mais adequadamente as formas religiosas tradicionais e populares no país, suas diversidades internas, como uma tentativa de conferir a elas o peso que possuem. Tal perspectiva abriria novas possibilidades para os diálogos inter-religiosos especialmente porque redesenharia os imaginários que o pluralismo religioso cria com a máxima "somos todos iguais". Neste sentido, da mesma forma que a reunião de grupos religiosos para diálogo e participação social conjunta pode, ao ocultar diferenciais de poder entre eles, gerar formas veladas de dominação, a compreensão moderna reducionista de religião, não devidamente aplicável aos grupos tradicionais, pode ser outra forma de artificialidade que afeta os processos de diálogo inter-religioso.

A crítica à concepção religiosa moderna e ocidental, especialmente pela carga ideológica e de supremacia que possui, não deve imobilizar as aproximações de grupos de diferentes tradições religiosas. Pensadores como a teóloga oriental Kwok Pui-Lan argumentam que as religiões que se organizam em contextos hegemônicos, como o cristianismo, a despeito dos séculos de abusos engendrados pelo colonialismo e da violência das posturas fundamentalistas ainda vigentes em nossos dias, têm uma contribuição importante para com o futuro da sociedade global. Todavia, é necessário que seja empreendido um movimento de descolonização da própria religião. Para tanto, tendo em vista a complexidade dos fenômenos religiosos atuais, para a autora "faz-se mister um exame mais acurado 
de como a religião é compreendida e de como as fronteiras religiosas tem sido construídas no Ocidente" [...] "A palavra não foi usada frequentemente até o Iluminismo, quando surgiu a necessidade de diferenciar o religioso do secular. Em seu uso moderno, a religião frequentemente conota uma série de crenças religiosas e uma comunidade institucionalizada" (PUI-LAN, 2015, p. 13).

A autora destaca que as formas de diálogo têm muito a ganhar em consistência com as críticas elaboradas pelos estudos pós-coloniais, sobretudo no que tange as reflexões em torno do tema da alteridade. Nas suas palavras:

Conforme vimos, na história do Ocidente, a ideia do outro diferente quanto à religião, rotulado quer de "pagão", que de "infiel", quer de "bárbaro", tem sido usada como escada para reforçar a identidade cristã e a hegemonia europeia. A descoberta desse religioso outro caminhou de mãos dadas com o encontro da Europa com outras partes do mundo. As religiões mundiais do islamismo, hinduísmo, budismo e confucionismo são mapeadas em geografia distante e em países estranhos, nos quais as pessoas vivem com superstições e costumes bizarros. O agrupamento de populações enormes sob uma única rubrica religiosa, com características identificáveis, tornou mais fácil a gestão da diferença religiosa para o controle colonial. O diálogo interfé se beneficiaria das intuições de estudos pós-coloniais, que questionam como o eu e o outro, o centro e a periferia, o dominador cultural e o marginalizado foram construídos (PUI-LAN, 2015, p. 32-33).

Tais questões se colocam, entre outras razões, pelo fato de que precisamos nos ater a um questionamento corrente se a atual valorização do pluralismo religioso, e de seus imaginários correspondentes, não se dá concomitantemente à perda de força política e social das religiões. Na mesma direção se questiona se tal valorização não seria uma forma de ocultar a perda de significado social da religião na atualidade, diante da força imperial do sistema econômico.

Na sequência de nossas reflexões, consideramos necessária uma síntese das teses que identificam o capitalismo como religião, pois, associada às críticas aos aspectos ideológicos que se confiram na noção de "o" Ocidente e às limitações da noção moderna de religião, elas poderiam contribuir para se descortinar elementos ideológicos presentes na formação dos imaginários gerados em torno dos diálogos inter-religiosos. 


\subsection{A força religiosa do capitalismo globalizado}

As experiências religiosas na atual sociedade globalizada apresentam-se fortemente influenciadas não somente pelo modelo econômico vigente, mas pela estrutura capitalista em seu sentido mais amplo como um sistema econômico, social e cultural. Por isso, reconhecemos que as análises científicas da religião - e aqui se encontram também as avaliações sobre os imaginários decorrentes dos diálogos inter-religiosos - não podem prescindir da relação com a economia, especialmente a força sedutora do capitalismo globalizado como instrumento de massificação e uniformização dentro de um quadro crescente de diversidade religiosa. O capitalismo, como sistema cultural e econômico, aprecia e apoia formas de pluralismo, incluindo o religioso, quando estas não se colocam em antagonismo com ele. Evidenciam-se cada vez mais a privatização da experiência colocada no indivíduo como sujeito autônomo da sua fé e um jogo ilusório de opções dentre as ofertas do mercado religioso. Isso porque tal escolha acontece com base nos aspectos que agradam a cada pessoa ou grupo e que contribuem para a recomposição de seus mundos e para a integração deles em uma variada coloração religiosa. As experiências de diálogo inter-religioso não estão isentas desta tendência.

Tal perspectiva confirma, em certo sentido, as teses que, ao seguirem Walter Benjamin (2013) e Paul Tillich (1956), defendem a ideia da força do sistema capitalista como religião (LÖWY, 2014; YIP, 2010; HINKELAMMERT, 2012), subtraindo dela a importância na organização da vida. No entanto, as religiões como tais, em suas diferentes tradições e sistemas, mantêm polos significativos de presença pública, ora como manutenção do status quo, ora como força de contestação social.

Esta visão esteve fortemente presente nas reflexões no interior da Escola de Frankfurt. Paul Tillich, por exemplo, afirmara que o capitalismo cumpre as mesmas funções da religião. Para ele, o mesmo poderia ocorrer com o socialismo 
ou outro sistema político ou cultural. Tal perspectiva foi muito bem sintetizada pelo teólogo vietnamita Francis Ching-Wah Yip na obra cujo título é emblemático: $O$ Capitalismo como religião? Um estudo da interpretação da modernidade em Paul Tillich (2010). Na visão de Tillich, todas as dimensões que digam respeito às preocupações últimas da vida são religião. Uma análise apurada do capitalismo revela que ele possui elementos que responderiam às preocupações últimas da existência humana. Tais respostas, assim como as demais respostas humanas, precisariam passar pelo crivo da crítica teológica, e, com isso, se poderia avaliar se corresponderiam a respostas integradoras ou destrutivas da dimensão humana.

No tocante ao pensamento de Walter Benjamin, Michael Löwy (2013), estudioso das teses do autor, ressalta que o referido filósofo foi um dos primeiros pensadores a questionar o conceito de linearidade da história e com isso se tornar um problematizador do mito do progresso. A história, se considerados os espaços fronteiriços dela, revela mesclas entre as dimensões pré-modernas e modernas, o que inibe a linearidade do progresso. Passado e presente se intercruzam, o que gera algo de imprevisibilidade e ineditismo na história, daí a crítica ao caráter totalizador e escatológico do capitalismo.

Löwy (2013) destaca que, apesar de ter sido Ernest Bloch o primeiro a se referir ao termo "capitalismo como religião" para criticar o calvinismo, foi Walter Benjamin quem o divulgou. A partir da articulação das perspectivas teóricas de Max Weber e Karl Marx, Benjamin afirmara que o capitalismo é uma religião. No famoso fragmento "O capitalismo como religião", ele ressalta alguns aspectos dessa tese. O primeiro é que o capitalismo possui uma estrutura religiosa, visão que ultrapassa as interpretações de Weber, para quem a religião apenas influencia o sistema econômico. Se, para Weber, o capitalismo teria sido fruto da secularização, na percepção de Benjamin ele é uma religião em si. Nesse sentido, a secularização não diria respeito ao desencantamento do mundo, haja vista que para o autor o capitalismo (re) encanta o mundo. 
O segundo aspecto é que o capitalismo é uma religião cultural; ou seja, na sociedade capitalista a ideologia burguesa é plasmada por todo o tecido social, se transformando em cultura. O sistema econômico perpassa as relações dos indivíduos, grupos e instituições e marca presença como uma cosmovisão mercantil e de prosperidade. Dessa forma, se reforçam os processos de reificação, por intermédio dos quais as pessoas se tornam coisas e as coisas ganham ar de pessoalidade. A cultura capitalista engendra movimentos de "naturalização" da ideologia mercantil, em que as pessoas assumem para si a condição sacrificial de mercadorias.

O terceiro aspecto é aquele do capitalismo como religião cultual. Benjamin (2013) afirma que as sociedades capitalistas são organizadas com práticas de adoração e louvação permanente. As próprias imagens nas notas de dinheiro sugerem imagens religiosas. Para o autor, "o capitalismo é uma religião puramente cultual talvez até a mais extremada que já existiu. Nele, todas as coisas só adquirem significado na relação imediata com o culto, ele não possui nenhuma dogmática, nenhuma teologia. Sob esse aspecto, o utilitarismo obtém sua coloração religiosa” (BENJAMIN, 2013, p. 21). Em geral se reconhece que quanto mais dogmática ou “teológica” for uma experiência religiosa, menos cultual ela será, daí a concepção de Benjamin do capitalismo ser religião sem teologia, justamente por não possuir limites. Ele funciona permanentemente desde a ostentação mercadológica do corpo à competição irrestrita em todas as áreas da vida.

No contexto latino-americano, as reflexões sobre religião e economia também se deram com vitalidade. Como já referido, nós destacamos tal perspectiva porque consideramos que os diálogos inter-religiosos em nosso contexto quase sempre são efetivados com a presença - no caso de algumas experiências diríamos com a iniciativa ou hegemonia - de grupos cristãos. Nossa pressuposição é que o amálgama Ocidente-modernidade-cristianismo-capitalismo molda concepções básicas que interagem diretamente nos processos de aproximação inter-religiosas. Em geral, tal incidência oculta os diferenciais de poder entre as diferentes 
expressões religiosas, o que reforça a noção ideológica de que os diálogos são feitos em plano similar e justo.

No âmbito latino-americano, o destaque no debate da relação entre religião e economia foram as reflexões que surgiram especialmente nos anos de 1980 em torno do Departamento Ecumênico de Investigação (DEI), na Costa Rica, com os trabalhos de Hugo Assmann e Franz Hinkelammert. A obra Idolatria do mercado: ensaio sobre economia e teologia (1989), dos dois autores, é exemplar desse processo.

Diante dessas considerações, nossas reflexões residem, por um lado, na valorização do pluralismo religioso e na análise das formas explicitamente religiosas, e, por outro, no alargamento da compreensão do conceito de religião, estendendo-o à visão de que o capitalismo representa uma religião. Embora não sejam mais as expressões religiosas como tais o fator que, em última instância, determina a organização e a reorganização da vida social, e sim o sistema econômico, tal perspectiva - o capitalismo como religião - não anula a importância das religiões como tais nos processos que interferem no aprofundamento da democracia e na defesa e ampliação de direitos, assim como em outros aspectos fundamentais da vida. O mesmo nós podemos afirmar em relação às aproximações inter-religiosas para diálogo e ações conjuntas.

Pela força histórica que possuem e pelo entrelaçamento com a cultura em diferentes níveis, as experiências religiosas têm sido molas propulsoras ou legitimadoras de processos sociais os mais diversos. Por isso, a nossa atenção ao pluralismo religioso em geral, tanto no tocante às formas mantenedoras do status quo, como aquelas que, especialmente a partir de experiências de diálogo e participação social conjunta, cumprem um papel crítico em relação aos sistemas que reforçam a dominação humana. Portanto, como vemos, o pluralismo religioso vai muito além da tarefa de elencar e de descrever os grupos religiosos específicos uma vez que possui facetas por demais variadas e complexas, que precisam ser 
compreendidas e articuladas para favorecer a geração de imaginários mais dialógicos e justos.

\subsection{Pluralismo religioso e globalização}

O contexto no qual emergem as relações entre religião e economia não se restringe a realidades locais ou nacionais, mas está integrado aos processos de globalização. Eles, por suposto, são complexos e de difícil análise, mas há no campo teológico certa atenção a eles. Para as nossas reflexões sobre como ocorre a relação entre diferenciais de poder e imaginários no tocante as experiências interreligiosas, consideramos necessária uma abordagem sobre a globalização econômica. Na busca de mediações socioanalíticas para compreensões teológicas mais apuradas, consideramos algumas vozes de destaque. Kwok Pui-Lan, em Globalização, gênero e construção da paz: o futuro do diálogo interfé (2015), mostra que

A rápida ascensão dos meios de comunicação social, juntamente com os meios tradicionais e digitais, conecta instantaneamente pessoas que vivem em países distantes no que foi chamado de "aldeia global". O termo globalização tornou-se corrente nos anos de 1990, no final da Guerra Fria, porque as antigas demarcações de primeiro, segundo e terceiro mundos tornaram-se obsoletas. Com o colapso da antiga União Soviética e com o realinhamento do bloco de países do leste europeu, algumas pessoas acreditaram que o capitalismo e o mercado neoliberal dominariam o mundo. Outros consideravam que a globalização é a modernidade acelerada e erguida a nível mais elevado. A globalização significa o alcance global do capitalismo, os rápidos fluxos de capital e de pessoas, o livre mercado e a ruptura das fronteiras nacionais. Debatem-se acaloradamente os efeitos da globalização. Alguns estudiosos apresentaram a crítica de que a globalização não é nova, mas uma continuação do neocolonialismo ocidental em forma mais concentrada. Outros, porém também ressaltaram que a globalização não está limitada à esfera econômica, mas tem dimensões sociais, culturais e políticas. A globalização também tem efeitos benignos, tais como a promoção de movimentos transnacionais básicos, da democracia e dos direitos humanos, e a proteção da biodiversidade e do meio ambiente (PUI-LAN, 2015, p. 9-10).

Franz Hinkelammert, na mesma direção, com o seu livro Mercado versus direitos humanos (2014), caracteriza esse processo da seguinte forma: 
A estratégia do capital através das empresas transnacionais que surgem a partir dos anos 60, 70, e que tem grande peso a partir do final dos anos 70, transformou-se na chamada estratégia de globalização ao conseguir um domínio tal sobre os governos, que estes a impuseram universalmente. Enquanto consegue impor-se aos governos, estes a impõem a seus cidadãos como estratégia obrigatória. Com isso a democracia se esvazia. Os cidadãos que se opõem são vistos como inimigos, inclusive inimigos que devem ser eliminados (HINKELAMMERT, 2014, p. 85).

Diante dessas visões, e para uma compreensão mais ampla dos processos de globalização, por um lado, e o esforço de compreender o lugar da religião propriamente dita na sociedade globalizada, por outro, seguimos também uma advertência de Alberto Moreira. Trata-se de olhar os processos de globalização a partir do que ele chamou "interpenetração das causalidades múltiplas", que leva em conta a articulação dos fatores econômicos, políticos e socioculturais. Nesse sentido, o autor segue Boaventura de Souza Santos, que nos chama a atenção que no tocante à globalização "é melhor pensá-la no plural" (MOREIRA, 2008, p. 20). $\mathrm{O}$ autor, em $O$ futuro da religião na sociedade global (2008), afirma que a primeira gama de teóricos que analisam os processos de globalização fundamenta seus argumentos na hipótese econômica. Um dos destaques desta corrente tem sido Immanuel Wallerstein, que especialmente em sua obra World-Systems Analysis: An Introduction (2004), afirma que, a partir do conceito sistema mundial, a globalização seria o motor do capitalismo. Na esteira destes pressupostos a globalização é entendida como um conjunto de processos que transformaram a formação social vigente no século 20. Tais transformações abarcam a dimensão ecológica, da divisão social do trabalho e a geopolítica, afetando diretamente com isso a compreensão do tempo e do espaço e os imaginários acerca dos diferentes aspectos da vida social. $\mathrm{O}$ dado religioso e as experiências inter-religiosas também estão neste contexto. Outro bloco de hipóteses destacam os fatores políticos. Nessa perspectiva "fatores como as normas de racionalização e progresso nas estruturas formais dos estados, ou seja, a questão do poder político, desempenham um papel decisivo no processo" (MOREIRA, 2008, p. 19). Ainda há que se considerar que devido às dinâmicas fragmentadoras da globalização, a expectativa e confiança nos Estados nacionais enquanto fontes 
de estabilidade e segurança foram minadas. Ou seja, o Estado perde a credibilidade e a capacidade de proporcionar conforto psíquico e identificação. Assim, sob o ponto de vista político desde a metáfora das territorialidades em fluxo, a globalização se configura pela crise dos poderes tradicionais, até então considerados legítimos. Articulada com esses dois fatores há também os fatores culturais. Neste aspecto, a globalização deve ser encarada "como um fenômeno primordialmente cultural: ela será um processo que impele o desenvolvimento inflacionado dos sistemas culturais acima de todos os outros" (MOREIRA, 2008, p. 19). As análises mais amplas e plurais ao levarem em conta os diferentes fatores possibilitam entender que a globalização excede às esferas das relações mais objetivas, tais quais as econômicas e políticas, encontrando explicações também nas dimensões de natureza mais acentuadamente subjetivas dos grupos sociais. Este bloco de interações interpela até mesmo a constituição identitária dos cidadãos e cidadãs. Nesse aspecto, as novas configurações religiosas são diretamente afetadas. Os diálogos inter-religiosos têm sido vistos como parte de destaque destes novos cenários.

\subsection{Experiências inter-religiosas, poder imperial e globalização contra- hegemônica}

No tocante às análises sobre os diferenciais de poder que marcam as relações inter-religiosas, consideramos que seja oportuno o debate sobre o poder imperial, as formas de globalização contra-hegemônica e como tais tensões incidem no contexto religioso.

Antônio Negri e Michael Hardt nos mostram, no livro Império (2001), que a nova realidade social e política do mundo globalizado é definida por uma forma de organização diferente da antiga hierarquia vertical, com um rei ou país no topo exercendo o poder sobre os demais. Ou também diferente das estruturas de poder que se configurava como uma árvore (ou seja, partindo de um tronco único para 
diversas ramificações ou galhos cada vez menores). Para os referidos autores, a nova forma de dominação, que eles denominam "Império", é constituída por redes assimétricas, cujos polos possuem maior poder do que outros, sendo que tal poder é desigual e desproporcional. Dessa forma, as relações de poder e de dominação se dão mais por via cultural e econômica do que pelo uso coercitivo de força, como era no passado. Os autores mostram que as entidades organizadas como redes, tais como corporações empresariais, organizações não governamentais e até mesmo grupos terroristas, têm mais poder e mobilidade nos dias de hoje e podem influenciar decisivamente, para o bem e para o mal, a sociedade e formar valores e visões de mundo. O Estado, partidos políticos e empresas tradicionais que valorizam a produção tornam espaços de menor poder e influência.

O poder econômico desigual e assimétrico passa a determinar os rumos da sociedade. As organizações em rede, porque estão mais facilmente adaptadas ao novo ambiente social gerado pela globalização, criam e recriam valores e visões de mundo e podem tanto ameaçar a vida humana, a democracia e a participação das pessoas e grupos quanto protegê-los. No entanto, não podemos nos esquecer que as redes que estão no segundo grupo, ou seja, aquelas que visam defender a vida e os valores humanos estão em enorme desproporção de poder se comparada com as grandes corporações econômicas.

Nós compreendemos a noção de Império a partir da identificação de um conglomerado de forças econômicas, políticas e simbólicas que convergem para um domínio total na sociedade exercido globalmente por elites de fortíssimo poder econômico e militar, sem fronteiras e sem limites. No caso da realidade globalizada em que vivemos hoje, seguimos as indicações de alguns autores que no livro Para além do espírito do Império: novas perspectivas em política e religião, afirmam que

Este Império global é o Império do capitalismo financeiro tardio, o eixo econômico que congrega, com seu poder virtual, os outros poderes: político, militar, cultural. Toda a diversidade do mundo reduz-se a uma 
única maneira lícita - para o Império - de gerir o econômico. A verdadeira rede que contém o Império é a rede financeira internacional: a isso devem submeter-se povos e expectativas, culturas e nações (MIGUEZ; RIEGER; MO SUNG, 2012, p. 29).

Não há no domínio imperial formas políticas institucionais específicas, um centro unificado, embora alguns países se destaquem pela assimilação da lógica do mercado financeiro, na qual o elemento da maximização do lucro ao estar no centro do sistema de valores e de visões de mundo está acima e na maior parte das vezes em contraposição ao sentido da vida humana, da natureza e dos direitos de ambos. Para isso, se evitam formas de controle da economia e políticas que regulem os exercícios do poder. "Esse esvaziamento do democrático, que é no fundo a anulação do político, é justamente o espaço onde se insere a possibilidade imperial. O democrático fica sem fundamento, passa a ser um significante vazio, fica sem uma ancoragem na realidade" (MIGUEZ; RIEGER; MO SUNG, 2012, p. 27).

Para o exercício do domínio, os grupos hegemônicos, ou seja, aqueles que detêm o poder e que, em boa parte das vezes estão invisíveis, desenvolvem suas práticas articulando as ações políticas e econômicas com certos símbolos, subjetividades e forças de comunicação que geram uma cosmovisão e uma forma de gerir a vida e a sociedade. É o que os autores acima denominam "o espírito do Império". A partir dele se criam condições de se negarem ou mesmo se anularem outros poderes, como o dos grupos subalternos, mulheres, jovens etc. Também se bloqueia o surgimento de opções políticas alternativas à dominação. Também dentro do espírito do Império não há lugar para dissensos, alteridades e antagonismos.

O conceito de Império se caracteriza por se colocar sem limites, acima da história, com pretensões de eternidade, presente em todas as realidades sociais. São grupos que se sentem no direito de regular e reger diretamente a natureza humana. Também buscam camuflar a sua violência inerente muitas vezes com um discurso artificial de igualdade, de paz e de desenvolvimento, sem levar em conta a justiça. Por essas razões é que o referido espírito, além de possuir um tipo próprio 
de "transcendência", essa ideia de estar acima, se reforçou ainda mais no espaço religioso, em função da ambiguidade da religião. As experiências religiosas podem contraditoriamente ir para um lado ou para o outro. Ou seja, da mesma forma que a religião dá garantia e legitimidade ao Império, absolutizando-o e não revelando a sua lógica cruel e sacrificialista, porque prejudica vidas, ela ao mesmo tempo surge como uma voz também transcendente, com uma dimensão profética, que se levanta como possibilidade e como espaço crítico.

Em oposição ao quadro de dominação cultural, política e econômica, há processos de globalização contra-hegemônica que ocorrem com a participação de vários e distintos grupos sociais. Neles há uma efetiva presença de grupos religiosos, que encontram em suas diferentes doutrinas justificativas para uma inserção social crítica ao sistema. É fato que há também as experiências que, ao contrário disso, reforçam e legitimam o sistema de dominação.

Os processos de globalização contra-hegemônica são difíceis de ser descritos, especialmente porque são diversos, muitos deles localizados em uma região ou outra, e nem sempre com estruturas centralizadas de articulação. No entanto, eles podem ser reconhecidos por serem um espaço de questionamento por intermédio de ideias e práticas sociais que visam identificar os danos maléficos da globalização econômica e por ser um espaço para propor alternativas para a sociedade. Em uma tentativa de lidar com essa complexidade, há, no campo político, o que é chamado de "espírito dos Fóruns Sociais Mundiais" (desde sua primeira edição na cidade de Porto Alegre, Brasil, 2001, até os dias de hoje). Ele está em oposição às políticas neoliberais coordenadas pelo Fórum Econômico Mundial e pelo Fundo Monetário Internacional, na sequência do "consenso de Washington”. Os movimentos em torno do Fórum Social Mundial, mesmo com suas contradições (devido à sua natureza ampla, variada e participativa), buscam articular a crítica ao sistema econômico e as lutas antissistêmicas, especialmente étnicas, raciais, sexuais, e as dos grupos minoritários que lutam por justiça. 
Boaventura de Souza Santos nos chama a atenção para o seguinte fato:

As lutas contra-hegemônicas pelos direitos humanos visam a mudança das estruturas sociais que são responsáveis pela sistemática de sofrimento injusto. São lutas materiais no sentido em que o seu ímpeto político deve dirigir-se à economia política subjacente à produção e à reprodução de relações sociais desiguais, mesmo quando essas relações estão menos direta ou linearmente ligadas à exploração capitalista e a uma hierarquia de base classista, como é o caso das relações que são objeto da política identitária convencional (discriminação sexual, racial, étnica, religiosa). São também lutas materiais no sentido em que pressupõem recursos políticos, financeiros e humanos para construir organizações e gerar militância (SANTOS, 2013, p. 134).

A presença de movimentos inter-religiosos ou de grupos com ênfases religiosas distintas tem sido de certo destaque e força no contexto dos movimentos e polos contra-hegemônicos na sociedade (RIBEIRO, 2016).

Nesta perspectiva se ressalta uma distinção pouco tratada no contexto brasileiro que é entre as expressões 'diálogo inter-religioso' e 'diálogo inter-fés'. A primeira expressão já é, em certa medida, consagrada nos meios religiosos e acadêmicos no Brasil. A segunda, mais comum em outros continentes, possui maior densidade, pois aponta para maior dinamismo, espontaneidade e liberdade nas relações entre expressões religiosas distintas. Kwok Pui-Lan, na tentativa de superar os essencialismos ocidentais que definem o que seja a religião, excluindo outras experiências e alteridades "não oficiais" ou mais espontâneas, propõe, ao lado de outros autores, o diálogo interfé. Tal expressão revela que “as conversações e interações estão acontecendo entre pessoas que pertencem a credos, e não entre religiões em si, entre religiões como sistemas de crenças e práticas" (PUI-LAN, 2015, p. 21). Tal perspectiva colocaria todos os crentes e grupos em plano similar, e facilitaria com isso um diálogo mais autêntico e justo. Além disso, também é bom destacar que os diálogos acontecem em diversos níveis, "entre líderes religiosos em encontros ecumênicos, entre estudiosos em espaços acadêmicos e nas comunidades locais e não hierárquicas” (PUI-LAN, 2015, p. 25). 
Assim, para além das hierarquias religiosas e dos lugares comuns que circunscrevem o diálogo inter-religioso, e que, em boa parte das vezes, mantém escondidos os diferenciais de poder que ocupam cada sujeito e cada tradição na constelação plural das religiões, Pui-Lan afirma que "é imperioso para as pessoas de todos os credos trabalharem rumo a um futuro no qual a religião possa ser uma força não para a destruição, mas para o bem comum” (PUI-LAN, 2015, p. 32).

O debate sobre religião em geral e sobre o pluralismo religioso em particular está intrinsecamente ligado a esses aspectos. Experiências religiosas, com suas propostas de ações, com seus canais de interação com a sociedade e com o espaço público, e com suas ideias teológicas, indicam com força tanto a perspectiva crítica e profética anti-imperial como a de manutenção do status quo. As experiências religiosas ao valorizarem a vida humana e a natureza acima dos interesses econômicos e ao darem visibilidade às pessoas pobres e aos grupos subalternos de diferentes naturezas, contribuem para o desmascaramento do espírito do Império e expressam uma reserva de sentido contra-hegemônico. As iniciativas de diálogo inter-religioso têm dado sinais visíveis nestas direções, em especial o apelo à defesa dos direitos humanos e da terra e o aprofundamento da democracia para além dos aspectos formais (RIBEIRO, 2016). Ao mesmo tempo, e de forma variada e ambígua, estão outras fronteiras entre experiências religiosas e sociedade. Estas arestas são correlacionadas e formam imaginários em torno do pluralismo religioso. O nosso ponto de vista é que eles podem ser mais bem discernidos com os instrumentais de análise que venham a questionar a construção ideológica da noção do Ocidente, os limites da concepção moderna de religião, a força religiosa, simbólica e prática, do capitalismo globalizado e o potencial anti-imperial e contrahegemônico das experiências religiosas, sobretudo inter-religiosas. 


\section{Polidoxia como elemento crucial para a reconstrução dos imaginários}

Para a abordagem teológica do pluralismo religioso, entendemos ser necessária a superação do binômio ortodoxia-heterodoxia, uma vez que este, em geral, gera formas excludentes. Quando a heterodoxia é vista como heresia a partir de mecanismos coercitivos institucionais das diferentes religiões, os processos de exclusão se acentuam. Considerando o contexto de hegemonia do amálgama Ocidente-modernidade-cristianismo-capitalismo, que já nos referimos, temos no conceito de polidoxia uma referência teológica importante para a construção de imaginários dialógicos no contexto das aproximações e diálogos inter-religiosos.

\subsection{0 que é polidoxia?}

Recorremos ao "termo polidoxia a fim de captar a ideia de que os cristãos não têm monopólio da revelação de Deus, e que a divindade deveria ser compreendida em termos de multiplicidade, irrestringibilidade e relacionalidade" (PUI-LAN, 2015, p. 74). Nesta direção, se reforça a diversidade, a pluralidade e a fluidez e a variedade da linguagem humana e suas falas acerca do sagrado. Pui-Lan afirma que

A polidoxia insiste que nenhuma teologia ou credo pode exaurir o sentido de Deus e alegar infalibilidade doutrinal. [...] A polidoxia partilha a afinidade com a teologia apofática, que insiste que a natureza de Deus não pode ser plenamente descrita, e que só podemos falar a respeito do que Deus não é, em vez de sobre o que Deus é (PUI-LAN, 2015, p. 75-76).

Com isso, por intermédio da polidoxia, Pui-Lan expõe os limites da razão ocidental, e nos apresenta a perspectiva de uma ética de alteridade. Ao demonstrar que a alteridade é constitutiva do ser - que, de fato, é sempre inter-ser - Pui-Lan nos mostra que o diálogo interfé é um canal de construção de uma cultura da solidariedade e da paz com justiça.

A autora defende que as religiões - a despeito dos séculos de abusos engendrados pelo colonialismo, e não obstante a violência dos fundamentalismos 
religiosos vigentes no passado e em nossos dias - podem contribuir efetivamente para um futuro de paz e de justiça da sociedade global. Conforme afirma a autora: "é imperioso para as pessoas de todos os credos trabalharem rumo a um futuro no qual a religião possa ser uma força não para a destruição, mas para o bem comum" (PUI-LAN, 2015, p. 32). A pressuposição das análises dela é que historicamente é possível constatarmos que as religiões estão se abrindo a uma postura dialogal. Esse processo está marcado por forças ambivalentes e ambíguas, haja vista que se por um lado encontramos os esforços ecumênicos de tantos organismos e grupos ao redor do mundo, como o Conselho Mundial de Igrejas, por exemplo, de outro também podemos visualizar os mais diversos esforços fundamentalistas que eclodem no seio da sociedade. O debate sobre a construção de novos imaginários ganha força na medida em que valorizamos a concepção que "se a religião quiser tornar-se uma força de construção da paz e não causa de intolerância e conflito, nova construção e novas relações com o 'outro diferente quanto a religião' devem ser buscadas" (PUI-LAN, 2015, p. 32).

Pui-Lan oferece vários elementos autocríticos para as avaliações dos movimentos ecumênicos, em especial no tocante às questões de gênero. Para a autora, ouvir as vozes das mulheres é indispensável, pois "desafortunadamente, em muitos encontros ecumênicos e no Parlamento Mundial de Religiões, a participação das mulheres e suas vozes foram marginalizadas" (PUI-LAN, 2015, p. 33). Assim, uma vez que historicamente o diálogo interfé tem sido predominantemente marcado pela majoritária presença masculina, a autora afirma que "o desafio do gênero é o desafio da alteridade, no qual a mulher, no diálogo, pode ser duplamente outra, se ela for mulher de outra crença em uma reunião constituída predominantemente por homens" (PUI-LAN, 2015, p. 35). Atenta as limitações e insuficiências dos esforços da "boa vontade", ou seja, ciente de que não basta "dar a voz" à outra pessoa para que o diálogo se estabeleça de forma justa e equitativa, Pui-Lan nos chama a atenção para dois conceitos fundamentais: os diferenciais de poder, já tratado em nossas análises, e a noção de apropriação. 
No tocante à noção de diferença de poder, Pui-Lan constata que "mulheres de credos diferentes não entram no diálogo em pé de igualdade” (PUI-LAN, 2015, p. 38). Para a autora, não basta nos colocarmos todos em posição de diálogo - a exemplo de mulheres cristãs e muçulmanas em torno de uma mesa, se não se levarmos em conta o lugar de onde cada pessoa ou grupo fala e age, e as diferenças de poder a que estão circunscritas. O que pode ocorrer é que ao invés de privilegiar a alteridade, se reforcem as subalternidades e a dominação. Para evitar este tipo de equívoco, Pui-Lan afirma que desde a gênese dos processos de diálogo é fundamental que sejam estabelecidas as linhas que orientarão o diálogo, explicitando e questionando os diferenciais de poder em questão, a fim de que haja uma descentralização e relativização do poder, de tal modo, que a outra pessoa ou grupo, não seja "constantemente forçada a comparar-se com a norma da maioria ou com a norma dominante" (PUI-LAN, 2015, p. 50). Além disso, como a autora afirma "no diálogo interfé, os participantes que pertencem à tradição dominante precisam instruir-se sobre as outras tradições religiosas a fim de conceder a todos as mesmas condições” (PUI-LAN, 2015, p. 51). “O reconhecimento recíproco está baseado no agir livre, despido de dominação e de exclusão, de modo que a liberdade de cada um fica protegida e garantida" (PUI-LAN, 2015, p. 82). Como exemplo, temos avaliações em torno do diálogo cristão-muçulmano:

o conhecimento acerca do complexo e multifacetado desenvolvimento das comunidades muçulmanas e das atividades das mulheres tornaria a mesa do diálogo mais acolhedora e aberta [...] As mulheres muçulmanas as vezes expressam mal-estar quando sentem que as mulheres cristãs estão impondo sua agenda "liberal". Na discussão dos papéis das mulheres em relação aos homens e na preferência sexual, algumas podem sentir-se incomodadas e pensar que não são tópicos adequados para o diálogo interfé. Portanto, expectativas e linhas de orientação claras devem ser estabelecidas no começo (PUI-LAN, 2015, p. 47).

A segunda contribuição crítica se refere à noção de apropriação. A este respeito, Pui-Lan afirma que "a mera inclusão de algumas vozes simbólicas, sem reconsiderar fundamentalmente as pressuposições e os esquemas epistemológicos atuantes não é verdadeira diversidade" (PUI-LAN, 2015, p. 52-53). Como exemplo 
poderíamos citar as apropriações indevidas realizadas pelas várias expressões da Nova Era e também de grupos cristãos para com as tradições nativas. Nas palavras da autora:

Hoje em dia, a apropriação indébita da espiritualidade indígena dá continuidade às mesmas práticas genocidas de seus ancestrais. Os rituais indígenas são tirados do contexto e empacotados novamente para consumo e lucro dos brancos, sem respeitar a integridade deles e seu uso nas comunidades indígenas (PUI-LAN, 2015, p. 57).

É comum em atividades e reuniões inter-religiosas, na ausência de representantes índios, a realização de momentos litúrgicos com canções, músicas e apresentações, como uma espécie de lampejos da cultura indígena. Ou seja, apropriam-se da cultura do índio mesmo que não demonstrem comprometimento efetivo e responsabilidade dialógica pelos povos nativos. De acordo com Pui-Lan isso ocorre por três razões básicas, que para ela se constituem como armadilhas: a) A negação: que a partir da ideia que os índios estão em extinção e, por isso, seja necessário proteger os elementos culturais do passado, para que sejam preservados na memória; b) A síndrome de querer ser índio: comum em culturas brancas que fetichizam as culturas nativas e o nativo através de imaginações românticas e utópicas - a exemplo do bom selvagem; e c) A culpa em busca de redenção - que levam pessoas brancas, cientes dos estragos realizados à cultura indígena, a se interessarem pelas culturas nativas a fim de que tenham os seus débitos emocionais sanados.

\subsection{Espiritualidades como projeções do devir}

Há outra noção que consideramos importante para melhor compreensão dos imaginários que emergem dos diálogos inter-religiosos. Trata-se da referência utópica e da dimensão da imaginação, que são forjadas nas fronteiras culturais. Homi Bhabha, um dos expoentes dos estudos culturais pós-coloniais, propõe, em $O$ local da cultura (2001), um alargamento de horizontes e de caminhos de reflexão sobre a realidade onde seja possível uma nova descrição da contemporaneidade 
humana, que supere o que em geral é visto como normalidade no presente. É o que o autor sugere como posicionar-se num além. Trata-se de uma atitude de revisão que permita retornar ao presente, reinterpretando-o, e redescrevendo a contemporaneidade com novas significações e possibilidades interventivas. $\mathrm{O}$ futuro é, nesse aspecto, assumido desde os entre-lugares culturais, com todas as instabilidades e indefinições que lhe são características.

De forma similar, Boaventura de Souza Santos, em sua obra A gramática do tempo (2010a) propõe uma dilatação do presente por intermédio de uma sociologia das ausências, mas ao mesmo tempo considera ser fundamental uma “contração do futuro" a partir do que ele chamou de sociologia das emergências. Esta é a investigação das alternativas sociais compatíveis com o horizonte das possibilidades concretas e, que "consiste em substituir o vazio do futuro segundo o tempo linear (um vazio que tanto é tudo como é nada) por um futuro de possibilidades plurais e concretas, simultaneamente utópicas e realistas, que se vão construindo no presente através de actividades de cuidado" (SANTOS, 2010a, p. 116).

Pressupomos que as identidades se constroem não mais nas singularidades - como as de classe, gênero etc - mas, nas fronteiras das diferentes realidades. Trata-se dos entre-lugares. Eles são compreendidos como um pensamento liminar, construído nas fronteiras, nas bordas das culturas. Pela natureza deles, não é simples caracterizar tal espaço cultural, mas eles podem se encontrar, por exemplo, na experiência da comunicação eletrônica entre jovens das camadas sociais pobres, que reúne duas dimensões de tempo distintas na vivência humana: o pós e o prémoderno. Ou na construção da cidadania a partir de expressões artísticas como o Funk, Hip-Hop, danças de rua, capoeira e formas de teatro popular, onde nem sempre o elemento racional de conscientização política está explícito. Crescem os grupos religiosos, especialmente entre a juventude, com diferentes tons nas visões teológicas, que se organizam e atuam nestas formas. Ou ainda podemos ver espaços fronteiriços nas experiências religiosas que agregam diferentes tradições, como 
aquelas que reúnem em uma só vivência o urbano, o afro e elementos tradicionais cristãos. Isto coloca em xeque as compreensões fixistas de identidades rígidas.

Mais uma vez, recorremos ao pensamento de Boaventura de Souza Santos:

Sabemos hoje que as identidades culturais não são rígidas nem, muito menos, imutáveis. São resultados sempre transitórios e fugazes de processos de identificação. Mesmo as identidades mais sólidas, como a de mulher, homem, país africano, país latino-americano ou país europeu, escondem negociações de sentido, jogos de polissemia, choques de temporalidades em constante processo de transformação, responsáveis em última instância pela sucessão de configurações hermenêuticas que de época para época dão corpo e vida a tais identidades. Identidade são, pois, identificações em curso (SANTOS, 2010b, p. 135).

A noção de hibridismo, para além da noção identitária branca, masculina e cristã do eu como ser autônomo, sugere a teoria do eu-em-relação. Pui-Lan, pautada na ideia de que todos somos híbridos, e que não há identidade pura ou isenta de intercambiamentos simbólicos, irá propor três razões pelas quais o hibridismo pode favorecer o diálogo interfé.

Em primeiro lugar, nossa identidade híbrida pode estimular conexões com membros de fora do nosso grupo. [...]. Em segundo lugar, a identidade híbrida leva em conta a identificação parcial de identidades sobrepostas, o que possibilita acontecer a colaboração para além das fronteiras religiosas. [...]. Em terceiro lugar, a identidade híbrida desafia a pureza que leva em conta a dupla ou múltipla pertença religiosa (PUI-LAN, 2015, p. 62-63).

Ainda em relação à noção de hibridismo, a autora novamente atenta para as armadilhas conceituais que muitas vezes surgem pelo caminho teórico. Para ela

[...] a compreenção de identidade híbrida aponta para a formação da identidade como um processo dinâmico e fluido, de tal modo que as pessoas podem mudar ao longo do tempo como resultado da interação com outros. No diálogo interfé, às verzes há o receio de que perderemos nosso compromisso religioso se formos abertos a outras tradições. Esse temor, no entanto, baseia-se em uma compreenção estática do eu. Se compreendermos o eu como uma rede de relações a interagir constantemente com outras, seremos mais abertos à transformação e à mudança (PUI-LAN, 2015, p. 64). 
A autora prossegue ao recorrer à noção de ambivalência. "O hibridismo sempre tem uma dimensão de ambivalência, porque significa a fragmentação do sujeito nos circuitos do poder na época colonial” (PUI-LAN, 2015, p. 66). Isso para evitar de incorrer em relativismos multiculturalistas que porventura possam instrumentalizar o pluralismo religioso, assimilando-o à lógica imperial do capitalismo globalizado e/ou as formas religiosas hegemônicas, invariavelmente cristãs. Portanto, "quando se suprimem o contexto colonial e o corte político do hibridismo, é possível ser facilmente cooptado para glorificar o pluralismo e a multiplicidade em nosso mundo globalizado, com livre movimento de comércio e de capital" (PUI-LAN, 2015, p. 67).

As duas visões descritas - a noção de polidoxia e a referência utópica associada à dimensão da imaginação forjada nas fronteiras culturais - reforçam a visão pluralista em relação às diferenças religiosas e às possibilidades de diálogo. Para uma interpretação teológica do pluralismo religioso, em especial o potencial utópico das experiências inter-religiosas e o diálogo interfé, levamos em conta a visão pluralista que nem anula as identidades religiosas, por um lado, e nem as absolutiza, por outro. A perspectiva pluralista olha as religiões em plano dialógico, considerando cada contexto, especialmente os diferenciais de poder que neles estão presentes. Não se trata de igualdade de religiões, mas de relações justas, dialógicas e propositivas entre elas.

\section{Considerações finais: por um reforço do imaginário pluralista}

Os resultados de nossa pesquisa visaram sistematizar duas noções em torno das relações inter-religiosas que cooperam na desconstrução de imaginários de corte idealista que muitas vezes emergem de práticas e de formas de ecumenismo inter-religioso. A primeira se baseia nos diferenciais de poder presentes na sociedade e nas relações inter-religiosas. Estes, uma vez identificados, assumidos e equacionados criticamente poderiam atenuar a reprodução de formas veladas de dominação, na medida em que tais formas, contraditoriamente, também estão 
presentes no espectro do diálogo inter-religioso. A segunda, a concepção de polidoxia, evitaria interpretações e ações dicotômicas e bipolares no tocante às aproximações inter-religiosas. Ela, constituída por intermédio da crítica e do desmascaramento do pensamento único, visa a ultrapassar o binômio ortodoxia/heresia, que em geral inibe a efetivação de um diálogo inter-religioso e cultural autêntico. A divindade, nesta perspectiva, é compreendida em termos de multiplicidade, irrestringibilidade e relacionalidade.

Nesse sentido, tendo em vista o leque de questões disputadas nesse debate, advogamos a visão de que cada expressão religiosa tem sua proposta salvífica e de fé, que devem ser aceitas, respeitadas, valorizadas e aprimoradas a partir de um diálogo justo e aproximação mútuas. Tal perspectiva não anula nem diminui o valor das identidades religiosas - no caso da fé cristã, majoritária em terras brasileiras, a importância de Cristo -, mas as leva a um aprofundamento e amadurecimento, movidos pelo diálogo e pela confrontação justa, amável e corresponsável. Assim, a fé cristã, por exemplo, seria reinterpretada a partir do confronto dialógico e criativo com as demais fés. O mesmo deve acontecer com toda e qualquer tradição religiosa.

$\mathrm{Na}$ visão pluralista, os elementos-chave da vivência religiosa e humana em geral são alteridade, respeito à diferença e o diálogo e cooperação prática e ética em torno da busca da justiça em relação a grupos empobrecidos e subjugados pelas mais diferentes formas de dominação e pela busca do bem comum. A aproximação e o diálogo entre grupos de distintas expressões religiosas cooperam para que elas possam construir ou reconstruir suas identidades e princípios fundantes. Daí nossa ênfase no diálogo justo como condição imprescindível para se construir uma identidade autêntica, levando em conta os diferenciais de poder entre cada expressão religiosa. As diferentes perspectivas e expressões religiosas poderiam, a partir do diálogo, reconstruir permanentemente suas contribuições para o mundo, dentro dos critérios da justiça, da paz e da integridade da criação. 
A visão pluralista recupera o sentido da gratuidade e nos leva à indicação da presença - e, ao mesmo tempo, a necessidade - de uma espiritualidade que possa corresponder aos processos sociopolíticos de aprofundamento democrático, de consolidação de direitos, de crítica às mais variadas formas de dominação, e à busca de alternativas à lógica imperial econômica. Tais visões de espiritualidade se expressam em aspectos práticos e concretos da vida social e política, como os processos de defesa da justiça social e econômica, dos direitos humanos e da terra, da cidadania e da dignidade dos pobres. Elas reforçam, não obstante suas limitações e ambiguidades, espaços de consciência social, alteridade, coexistencialidade, cordialidade, humanização e integração cósmica. Todos eles cooperam na reconstrução de imaginários e interpelam concretamente as práticas sociais.

\section{REFERÊNCIAS}

BENJAMIN, Walter. O capitalismo como religião. São Paulo: Boitempo, 2013.

BHABHA, Homi. O Local da Cultura. Belo Horizonte: Editora UFMG, 2001.

HALL, Stuart. Formations of Modernity. Oxford, UK, Blackwell Publishers, 1992.

HARDT, Michael; NEGRI, Antônio. Império. Rio de Janeiro: Record, 2001.

HINKELAMMERT, Franz; ASSMANN, Hugo. Idolatria do mercado: ensaio sobre economia e teologia. Petrópolis: Vozes, 1989.

HINKELAMMERT, Franz. A maldição que pesa sobre a lei: as raízes do pensamento crítico em Paulo de Tarso. São Paulo: Paulus, 2012.

HINKELAMMERT, Franz. Mercado versus direitos humanos. São Paulo: Paulus, 2014 .

LÖWY, Michael. "Prefácio: Walter Benjamin, crítico da civilização" (p. 7-19). In: BENJAMIN, Walter. $O$ capitalismo como religião. São Paulo: Boitempo, 2013.

LÖWY, Michael. A jaula de aço: Max Weber e o marxismo weberiano. São Paulo: Boitempo, 2014.

MIGUEZ, Nestor; RIEGER, Joerg; MO SUNG, Jung. Para além do espírito do Império: novas perspectivas em política e religião. São Paulo: Paulinas, 2012. 
MOREIRA, Alberto da Silva. "O futuro da religião no mundo globalizado". In: MOREIRA, Alberto da Silva \& DIAS DE OLIVEIRA, Irene (orgs.). O Futuro da Religião na

Sociedade Global. São Paulo: Paulinas/UCG, 2008.

PUI-LAN, Kwok. Globalização, gênero e construção da paz: o futuro do diálogo interfé. São Paulo: Paulus, 2015.

RIBEIRO, Claudio de Oliveira. Religião, democracia e direitos humanos: presença pública inter-religiosa no fortalecimento da democracia e na defesa dos direitos humanos no Brasil. São Paulo: Reflexão, 2016.

SANTOS, Boaventura de Souza. A gramática do tempo: para uma nova cultura política. São Paulo: Cortez, 2010a.

SANTOS, Boaventura de Souza. Pela mão de Alice: o social e o político na pósmodernidade. São Paulo: Cortez, 201ob.

SANTOS, Boaventura de Souza. Se Deus Fosse um Ativista dos Direitos Humanos. São Paulo: Cortez, 2013.

TILLICH, Paul. The Religious Situation. New York: Meridian Books, 1956.

WALLERSTEIN, Immanuel. World-Systems Analysis: An Introduction. Durham \& London: Duke University Press, 2004.

YIP, Francis Ching-Wah. Capitalism as religion? A study of Paul Tillich's interpretation of modernity. Massachusetts: Harvard, 2010. 